https://doi.org/10.15407/ujpe66.5.369

A. KUMAR

National Defence Academy, Faculty of Sciences (Physics)

(Khadakwasla, Pune-411023, India; e-mail: ashuphys@gmail.com)

\title{
THERMODYNAMIC MIXING PROPERTIES OF Li-Mg BINARY ALLOY
}

\begin{abstract}
Theoretical calculations of thermodynamic mixing properties viz., Gibbs' free energy of mixing $G_{M}$, heat of mixing $H_{M}$, entropy of mixing $S_{M}$, as well as the activity and its coefficients, are performed using the Bhatia-Hargrove complex formation model. The mixture is assumed to be pseudobinary. The components exhibit a negative deviation from Raoult's behavior, and the system is weakly interacting in nature.

Ke ywords: Li-Mg binary alloy, Gibbs' free energy of mixing, heat of mixing, entropy of mixing, Raoult's behavior.
\end{abstract}

\section{Introduction}

The thermodynamic properties of binary alloys have been a subject of great theoretical interest. Many researchers concentrated on their study in exploring the entropy of mixing of alloys with equiatomic composition, whereas, theoretically, the most interesting features of the thermodynamic properties are their changes, as the composition varies. Mg-based alloys have been a matter of investigation [1-4] due to their immense technological and commercial importance. Changing the crystal structure from hcp to either fcc or bcc is one way to make Mg more useful. Cubic $\mathrm{Mg}$ would be of more workable at room temperature, owing to a higher number of available slip systems, and less prone to form disadvantageous deformation textures. These changes would make cubic $\mathrm{Mg}$ very attractive from a manufacturing point of view [5]. During the past decades, the system Li-Mg has been a subject of interest both from experimental and theoretical viewpoints. The system exhibits an intermediate behavior between the segregative systems and the compound-forming ones [4]. Recently, some single-crystal elastic constants are calculated at zero temperature using the Density Functional The-

(C) A. KUMAR, 2021

ISSN 2071-0194. Ukr. J. Phys. 2021. Vol. 66, No. 5 ory (DFT) by Counts et al. [5]. Moreover, the calculations of the electrical resistivity (HFP technique) and electronic structure of $\mathrm{Li}-\mathrm{Mg}$ alloy with regard for its composition have been performed by $\mathrm{A}$. Kumar et al. [4] employing the full-potential linearized augmented plane wave method (FLAPW).

In our previous publications [6-8], we mainly emphasized our work on Mg-based alloys viz., $\mathrm{Cu}-\mathrm{Mg}$, $\mathrm{Ca}-\mathrm{Mg}$, and $\mathrm{Al}-\mathrm{Mg}$, with special attention to thermodynamics, the electronic transport, and structural and surface properties using the complex formation model proposed by A.B. Bhatia and W.H. Hargrove [9]. In continuation of our previous work [4], we are going to present a detailed study of the thermodynamic mixing properties, as well as the activity and its coefficients of $\mathrm{Li}-\mathrm{Mg}$ binary alloy using the complex formation model proposed by A.B. Bhatia and W.H. Hargrove [9] and commonly referred as BhatiaHargrove technique.

\section{Computational Details}

The thermodynamic mixing properties viz., Gibbs' free energy of mixing $\left(G_{M}\right)$, heat of mixing $\left(H_{M}\right)$, the entropy of mixing $\left(S_{M}\right)$, activity and its coefficients have been studied through the Bhatia-Hargrove technique [9]. In the complex formation model, the liquid 
binary alloy $\mathrm{A}-\mathrm{B}$ is assumed to be a ternary mixture consisting of free atoms A, free atoms B and their preferential association, referred as a chemical complex $\mathrm{A}_{\mu} \mathrm{B}_{\nu}$.

Let us suppose that there are $n_{\mathrm{A}}\left(=n_{1} N\right)$ of free atoms $\mathrm{A}, \quad n_{\mathrm{B}}\left(=n_{2} N\right)$ of free atoms $\mathrm{B}$, and $n_{m}\left(=n_{3} N\right)$ number of chemical complexes in the mixture. Then the total number of scattering points is

$N_{S}=n_{\mathrm{A}}+n_{\mathrm{B}}+n_{m}=n N$,

where $N$ is the total number of atoms $\mathrm{A}$ and atoms B, i.e., $N=N_{\mathrm{A}}+N_{\mathrm{B}}$ and $n=n_{1}+n_{2}+n_{3}$ with

$$
\begin{aligned}
& n_{1}=1-C-\mu n_{3}, \\
& n_{2}=C-\nu n_{3} .
\end{aligned}
$$

Here, $C$ is the concentration of the second component.

The free energy of mixing $G_{M}$ can be written as

$$
\begin{aligned}
& G_{M}=-n_{3} g+R T \sum_{i=1}^{3} n_{i}\left(\ln n_{i}-\ln n\right)+ \\
& +\sum_{i<j} \sum \frac{n_{i} n_{j}}{n} W_{i j},
\end{aligned}
$$

where $g$ is the energy of formation of the complex, the first term $-n_{3} g$ represents the lowering of the free energy due to the formation of the complex in the alloy, and $W_{i j}(i, j=1,2,3)$ are the interaction energies. By definition, the latter are independent of the composition, although they may depend on the temperature and pressure, $R$ is the molar gas constant, and $n$ is the total number of atoms in the case of compound formation.

The equilibrium values of the chemical complex $n_{3}$ may be obtained through the condition

$$
\begin{aligned}
& \left(\frac{\partial G_{M}}{\partial n_{3}}\right)_{T, P, C}=0 \\
& \frac{n_{1}^{\mu} n_{2}^{\nu}}{n_{3} n^{\mu+\nu-1}}=e^{-g / R T} e^{Y},
\end{aligned}
$$

where

$$
\begin{aligned}
& Y=\frac{W_{12}}{R T}\left[(\mu+\nu-1) \frac{n_{1} n_{2}}{n^{2}}-\frac{\mu n_{2}}{n}-\frac{\nu n_{1}}{n}\right]+ \\
& +\frac{W_{13}}{R T}\left[(\mu+\nu-1) \frac{n_{1} n_{3}}{n^{2}}-\frac{\mu n_{3}}{n}+\frac{n_{1}}{n}\right]+ \\
& +\frac{W_{23}}{R T}\left[(\mu+\nu-1) \frac{n_{2} n_{3}}{n^{2}}-\frac{\nu n_{3}}{n}+\frac{n_{2}}{n}\right] .
\end{aligned}
$$

The equation can be solved numerically to obtain the equilibrium value of $n_{3}$. Once the expression of $G_{M}$ is obtained, other thermodynamic properties related to $G_{M}$ can be readily calculated as

$$
\begin{aligned}
H_{M} & =G_{M}-T\left(\frac{\partial G_{M}}{\partial T}\right)_{T, P, N}, \\
S_{M} & =\frac{\left(H_{M}-G_{M}\right)}{T} .
\end{aligned}
$$

The expression for the Gibbs' free energy of mixing can be used then to construct an equation for the thermodynamic activity using the relation

$$
\begin{aligned}
& R T \ln a_{A}=\left(\frac{\partial G_{M}}{\partial N_{A}}\right)_{T, P, N_{B}}= \\
& =\frac{1}{N}\left[G_{M}+(1-c)\left(\frac{\partial G_{M}}{\partial c}\right)_{T, P, N}\right] .
\end{aligned}
$$

The first thing to do is to fit values for the parameters $g$ and $W_{i j}$. In order to do this, we calculate firstly the value of $g$ at the chemical concentration $c=\mu /(\mu+\nu)$ using, as a starting point, $g \approx-(\mu+\nu) G_{M}$. The energy parameters $W_{12}, W_{13}$, and $W_{23}$ are then adjusted in order to reproduce, as closely as possible, the experimentally measured concentration dependence of the Gibbs' free energy of mixing. Once the energy parameters have been selected, they remain the same for any mixing.

In view of the convenience of the concept of activity and the simplicity of Raoult's law, it is convenient to define an additional thermodynamic function called the activity coefficient, $\gamma$. The activity coefficient of a component of the solution is defined as the ratio of the activity of the component to its mole fraction, i.e., for the component $i$,

$\gamma_{i}=\frac{a_{i}}{X_{i}}$

The value of $\gamma_{i}$ can be greater or less than unity $\left(\gamma_{i}=1\right.$ gives ideal Raoult's behavior). If $\gamma_{i}>1$, then the component $i$ is said to exhibit a positive deviation from Raoult's ideal behavior. If $\gamma_{i}<1$, then the component $i$ is said to exhibit a negative deviation from Raoult's law.

\section{Results and Discussions}

\subsection{Gibbs' free energy of mixing $\left(G_{M}\right)$ and interaction energies $\left(W_{i j}\right)$}

The result of the above computations has been presented in Fig. 1 for the inspection along with 


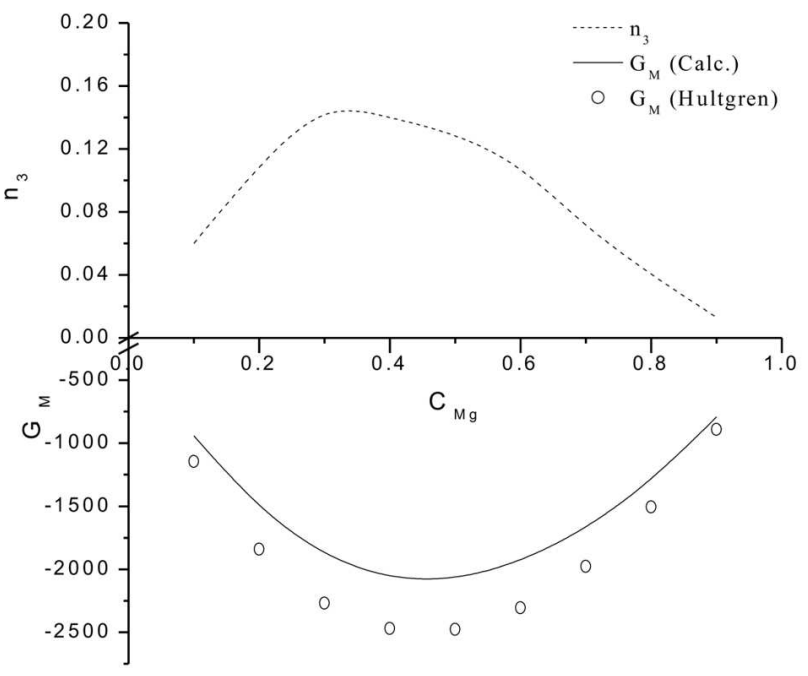

Fig. 1. Number of complexes $\left(n_{3}\right)$ and Gibbs' free energy of mixing $\left(G_{M} / R T\right)$ of Li-Mg liquid binary alloy $(1000 \mathrm{~K})$

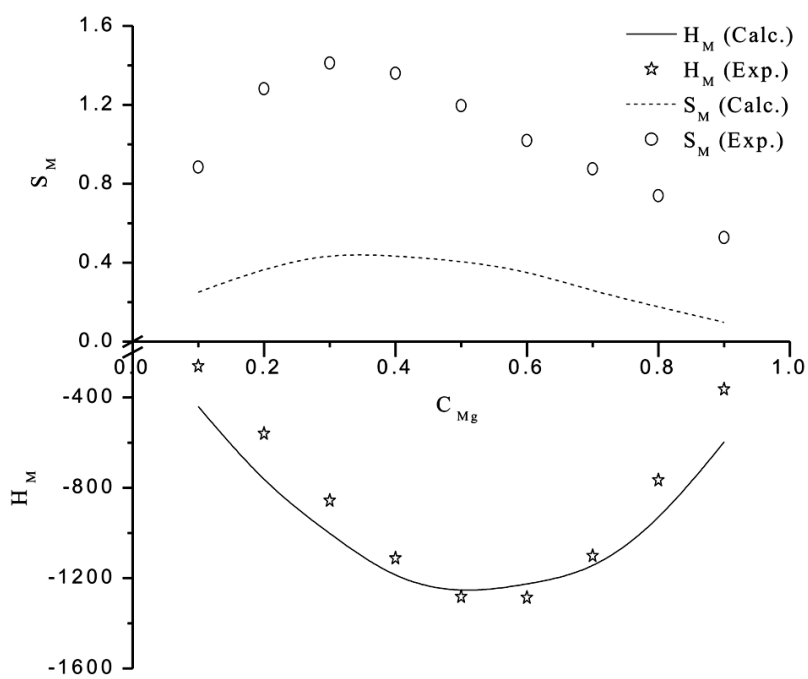

Fig. 2. Heat of mixing $\left(H_{M}\right)$ and entropy of mixing $\left(S_{M}\right)$ of $\mathrm{Li}-\mathrm{Mg}$ binary alloy

the experimental values of $G_{M}$ from R. Hultgren et al. [10]. The interaction energies obtained through the fittings are $W_{12}=-0.6, W_{13}=0.5$, and $W_{23}=$ $=-0.5$ and $g=1.60$ at $1000 \mathrm{~K}$ (in terms of $R T$ ). The exothermic mixing in an A-B binary system occurs, when the $\mathrm{A}-\mathrm{B}$ bond energy is more negative than both the $\mathrm{A}-\mathrm{A}$ and $\mathrm{B}-\mathrm{B}$ bond energies, and this causes a tendency toward the "ordering" in the solution, in which the A atom attempts to only have B atoms as the nearest neighbors and vice versa. Thus, the ISSN 2071-0194. Ukr. J. Phys. 2021. Vol. 66, No. 5

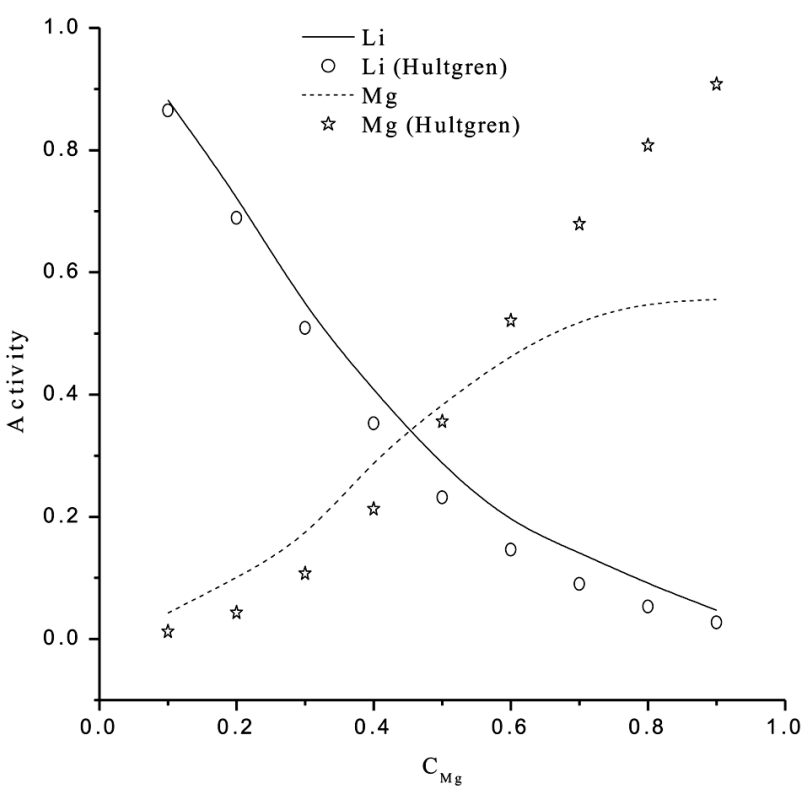

Fig. 3. Composition dependence of activities in the system $\mathrm{Li}-\mathrm{Mg}$ at $1000 \mathrm{~K}$

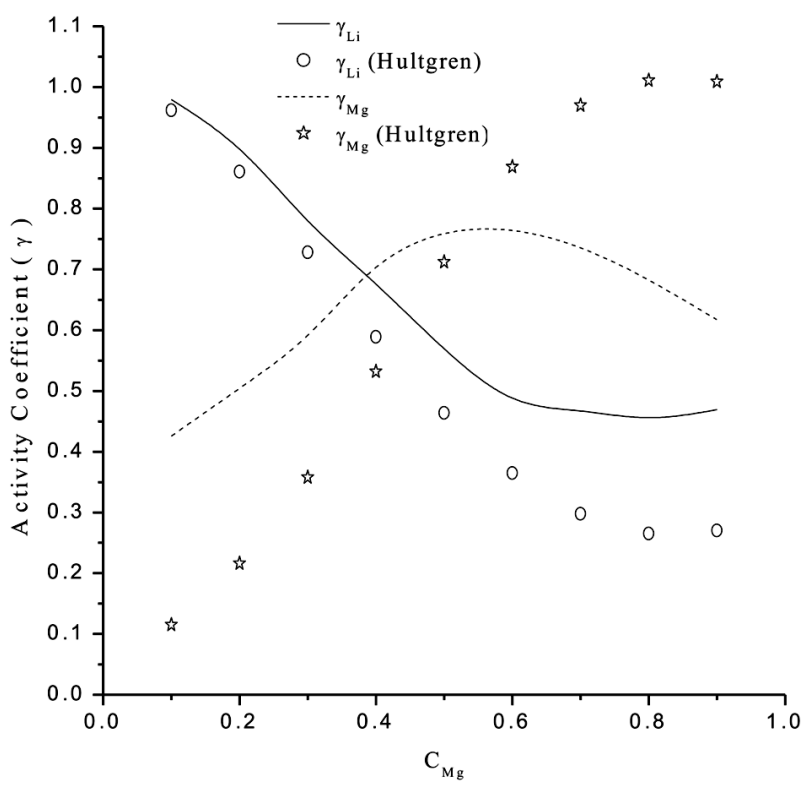

Fig. 4. Concentration dependence of the activity coefficients in $\mathrm{Li}-\mathrm{Mg}$ liquid binary alloy at $1000 \mathrm{~K}$

exothermic mixing indicates a tendency toward the formation of a compound between the two components. On experimental grounds, a smaller value of $g<3.5$ suggests that $\mathrm{Li}-\mathrm{Mg}$ is a weakly interacting system concerning the formation energy $g$, and 
it comes in the category of the $\mathrm{Mg}-\mathrm{Sn}, \mathrm{Al}-\mathrm{Mg}, \mathrm{Ag}-$ $\mathrm{Al}$, and $\mathrm{Cu}-\mathrm{Sn}$ systems in contrast to the strongly interacting systems like $\mathrm{Hg}-\mathrm{Na}, \mathrm{Hg}-\mathrm{K}, \mathrm{Mg}-\mathrm{Bi}$, etc.

Further, we observe that the interaction energies $W_{12}$ and $W_{23}$ are attractive, while $W_{13}$ is repulsive in nature. This also supports the weakly interacting nature of $\mathrm{Li}-\mathrm{Mg}$ alloy. The free energy of mixing $G_{M}$ shows a good agreement with the experiment (Fig. 1). We observe also that $G_{M}$ is symmetric for $\mathrm{Li}-\mathrm{Mg}$, while it is found to be asymmetric for alloys like $\mathrm{Al}-\mathrm{Ca}, \mathrm{Ca}-\mathrm{Mg}, \mathrm{Mg}-\mathrm{Zn}, \mathrm{Cu}-\mathrm{Mg}$, etc.

\subsection{Heat of mixing $\left(\mathrm{H}_{M}\right)$ and entropy of mixing $\left(S_{M}\right)$}

The heat of mixing is the amount of the heat absorbed from a thermostatted heat reservoir, per mole of the solution formed, at the temperature $T$. The heat of and entropy of mixing with respect to the composition at $1000 \mathrm{~K}$ along with the experimental data of Hultgren [10] are presented in Fig. 2. A perusal of Fig. 2 reveals that the calculated $H_{M}$ agrees well with the experimental data, and $S_{M}$ produces the same nature as the experimental one.

\subsection{Activity and activity coefficients}

Consider the value of $\gamma_{i}$ to be greater or less than unity ( $\gamma_{i}=1$ gives ideal Raoult's behavior). If $\gamma_{i}>1$, then the component $i$ is said to exhibit a positive deviation from Raoult's ideal behavior, and if $\gamma_{i}<1$, then the component $i$ is said to exhibit a negative deviation from Raoult's law. From Figs. 3 and 4, it is inferred that the components exhibit a negative deviation from Raoult's law.

\section{Conclusions}

- The system is weakly interacting in nature.

- The system exhibits a negative deviation from ideal Raoult's behavior.

- The exothermic mixing indicates a tendency toward the formation of a compound between the two components.

- In a solution, whose components exhibit negative deviations from the ideality, the activity coefficients increase with the temperature. Hence, the partial molar heats of mixing and the molar heat of mixing are negative. Such a solution is formed exothermically.
1. S.R. Agnew, M.H. Yoo, C.N. Tome. Application of texture simulation to understanding mechanical behavior of $\mathrm{Mg}$ and solid solution alloys containing Li or Y. Acta Mater. 49, 4277 (2001).

2. G. Gottstein. Physical Foundations of Materials Science (Springer, 2004) [ISBN: 978-3-662-09291-0].

3. M.J. Philippe, F. Wagner, F.E. Mellab, C. Esling, J. Wegria. Modelling of texture evolution for materials of hexagonal symmetry-I. Application to zinc alloys. Acta Metal. Mater. 42, 239 (1994).

4. A. Kumar, S.M. Rafique, T.P. Sinha. Electronic Transport and Ground State Properties of Li-Mg Binary Alloy. Chinese J. Phys. 47, 215 (2009).

5. W.A. Counts, M. Friak, D. Raabe, J. Neugebauer. Using ab initio calculations in designing bcc $\mathrm{Mg}-\mathrm{Li}$ alloys for ultralightweight applications. Acta Materialia 57, 69 (2009).

6. A. Kumar, S.M. Rafique, N. Jha, A.K. Mishra. Structure, thermodynamic, electrical and surface properties of $\mathrm{Cu}_{-}^{-}$ Mg binary alloy: Complex formation model. Physica $B$ 357, 445 (2005).

7. A. Kumar, S.M. Rafique, N. Jha. Study of glass forming tendency of $\mathrm{Ca}-\mathrm{Mg}$ binary alloy and its physical properties: Pseudomolecule formation model. Physica B 373, 169 (2006).

8. A. Kumar, S.M. Rafique, N. Jha, T.P. Sinha. Complex formation study of thermodynamical, structural properties and density of states of Al-Mg binary alloy. Physica B 404, 1933 (2009).

9. A.B. Bhatia, W.H. Hargrov. Concentration fluctuations and thermodynamic properties of some compound forming binary molten systems. Phys. Rev. B 10, 3186 (1974).

10. R. Hultgren, P.D. Desai, D.T. Hawkins, M. Gleiser, K.K. Kelley. Selected Values of the Thermodynamic Properties of Binary Alloys (ASM, 1973) [LCCN 73076588].

Received 26.04.20

\section{A. Кумар}

\section{ТЕРМОДИНАМІЧНІ ВЛАСТИВОСТІ ЗМІШУВАННЯ У БІНАРНОМУ СПЛАВІ Li-Mg}

На основі моделі Бхатіа-Харгроува виконано теоретичні розрахунки термодинамічних властивостей змішування, а саме, отримано величини вільної енергї Гіббса змішування, теплоти змішування, ентропії змішування, а також активності та її коефіцієнтів. Суміш вважається псевдобінарною. Компоненти демонструють негативне відхилення від поведінки Рауля, і система є фактично слабковзаємодіючою.

Kлючов $i$ слова: бінарний сплав Li-Mg, вільна енергія Гіббса змішування, теплота змішування, ентропія змішування, поведінка Рауля. 